\title{
The Relationship between Serum Estrogen Levels and Presence of Benign Lesions in Uterus Thyroid Gland and Breasts
}

\author{
Zeynep Nilufer TEKIN', Tuna DEMIRBAS ${ }^{2}$, Bercem AYCICEK ${ }^{3}$, Esin DERIN CICEK ${ }^{4}$ \\ Istanbul, Turkey
}

\section{ABSTRACT}

OBJECTIVE: We aimed to detect co-occurrence of uterine myomas, thyroid nodules and breast lesions and to investigate the association between these benign tumors with estrogen levels.

STUDY DESIGN: In this retrospective cohort study, records of 8008 premenopausal women were analyzed who admitted to the Darıca Farabi State Hospital for routine breast image investigation and which were performed by the same radiologist between 2011 and 2016. 251 patients who had both Thyroid and Pelvic Ultrasound (US) examinations in the same year were extracted from these 8008 patients. All data were obtained from file records and ICD-10 diagnosis code of the electronic database of the hospital. For breast examination, breast imaging reporting and data system (BIRADS) terminology was used.

RESULTS: The mean age of the patients at the admission to the hospital was $32 \pm 5.7$ years. From 251 patients only 9 patients had benign lesions in all 3 organs, whereas 63 patients had both thyroid nodules and breast lesions and 5 patients had thyroid nodules and uterine myoma, and 7 patients had BIRADS 2,3 lesions and uterine myoma, respectively. We only found a relationship between age and existence of myoma uteri and thyroid nodule. ( $p=0.008$, for both). Among hormones, only thyroid stimulating hormone was found to be lower in BIRADS 2,3 lesions than BIRADS 1 lesions $(p=0.017)$.

CONCLUSION: Our study did not show an association between estrogen levels and the presence of benign lesions in different organs according to the radiologic investigation in premenopausal women.

Keywords: Estrogen, Premenopausal women, Radiologic benign lesions, Ultrasound imaging

Gynecol Obstet Reprod Med 2019;25(2):107-111

${ }^{1}$ Department of Radiology Istanbul Medeniyet University Goztepe Training and Research Hospital Istanbul, Turkey.

${ }^{2}$ Department of Radiology University of Health Sciences Istanbul Bağcllar Training and Research Hospital Istanbul, Turkey.

${ }^{3}$ Department of Endocrinology and Metabolic Diseases University of Health Sciences Gazi Yasargil Training and Research Hospital Diyarbakır, Turkey.

${ }^{4}$ Department of Radiology University of Health Sciences, Istanbul Fatih Sultan Mehmet Training and Research Hospital Istanbul, Turkey.

Address of Correspondence: Zeynep Nilufer Tekin

Department of Radiology Medeniyet

University Goztepe Training and

Research Hospital 34720 Istanbul

Turkey

drnilufer@gmail.com

Submitted for Publication:

18. 09.2018

Accepted for Publication:

04. 02.2019

ORCID IDs of the authors:

Z.N.T.: 0000-0002-8209-0331. T.D.: 0000-0003-0934-2640

B.A.: 0000-0001-7085-5846. E.D.C.: 0000-0002-0391-3003

\begin{tabular}{|c|c|}
\hline Quick Response Code: & Access this article online \\
\cline { 2 - 2 } & Website: www.gorm.com.tr \\
e- mail: info@gorm.com.tr
\end{tabular}

How to cite this article: Tekin ZN. Demirbas T. Aycicek B. Derin Cicek E. The Relationship between Serum Estrogen Levels and Presence of Benign Lesions in Uterus, Thyroid Gland and Breasts. Gynecol Obstet Reprod Med 2019;25(2):107-111

\section{Introduction}

Uterine benign lesions are common, occurring in $70 \%$ of women by age 50 (1). The majority of benign lesions is asymptomatic and require no intervention or further investigation, but some result in menstrual abnormalities, iron deficiency anemia and bulk symptoms that are treated with hysterectomy as a definitive solution. The real frequency of benign lesions was reported to be $84 \%$ in 77 of 100 consecutive total hysterectomy specimens (2). Benign breast lesions such as fibroadenomas are frequently seen in young women less than 35 years of age. In $10-15 \%$ of the patients, multiple fibroadenomas are found in one or both breasts. Complaints of these women are usually round-shaped, smooth or lobulated contoured, relatively movable, painless masses (3).

Nodular thyroid disease is more frequent (5 to 15 fold) in women $(4,5)$. One study revealed that in iodine-deficient areas, nodular diseases are seen much more in adult women than in adult men (30-40\% and $20-30 \%$, respectively) (6). One of the reasons leading to this difference can be speculated by a direct impact of steroid hormones as well as genetic susceptibility for thyroid disease. In an animal experiment, estrogen has been shown in Frtl-5 cells and thyroid cell lines and has 
been suggested as a possible contributing factor related to gender $(7,8)$. Until now, only one study demonstrated the coincidence of benign lesions in different organs such as thyroid, uterus and breast (9). Furthermore, there was not any clinical study about the relationship between estrogen and the existence of benign lesions which was previously demonstrated mostly by in vitro studies.

The aim of our study was to detect firstly co-occurrence of uterine myomas, thyroid nodules, and breast lesions (fibroadenomas, cysts) based on breast imaging reporting and data system (BIRADS) classification in ultrasound (US) investigation in premenopausal women by the present clinical study and also it's the first time to investigate the association between existence of these benign tumors and estrogen levels in addition to gonadotrophins and thyroid hormones, as well.

\section{Material and Method}

Records of 8008 women were analyzed who admitted hospital for routine breast image investigation in between 2011 and 2016. In 1186 patients, thyroid examinations were performed by US at the same time. Along with this, 251 patients of whom pelvic US were concurrently performed were also evaluated. The 251 women, with benign lesions according to radiologic examination at least in two different organs including breast, thyroid or uterus, are included in the study. All data of the study were obtained from file records and ICD-10 diagnosis code of the electronic database of the hospital. This retrospective cohort study was undertaken in Darica Farabi State Hospital between January 2011 and February 2016. Postmenopausal women with malignant diseases and those who had insufficient reports and radiologic investigations which were performed by different radiologists, were excluded from the study.

\section{Main outcomes}

Firstly, to determine, the coincidence of benign lesions in different 3 organs including thyroid, breast and uterus; secondly, the relationship between existence of benign lesions and anabolic hormone (Estradiol) (E2) in addition to gonadotrophins and thyroid hormones.

\section{Biochemical analyses}

Venous blood is taken for gonadotropin hormone levels mostly on the $3^{\text {rd }}$ day of the follicular phase. If the patient had amenorrhea, blood samples were drawn on a random day. Serum Follicle-stimulating hormone (FSH) (N: 3.5-12.5 $\mathrm{mIU} / \mathrm{mL})$, Luteinizing hormone $(\mathrm{LH})(\mathrm{N}: 1.9-12.5 \mathrm{IU} / \mathrm{L}$, E2 (N:19.5-144.2 pg/mL), were measured by the chemiluminescence immunoassay using a Roche Diagnostics COBAS E601 with original reagents. Serum thyroid-stimulating hormone (TSH), free thyroxin (fT4) were assayed with electrochemiluminescence immunoassay (Roche Diagnostics COBAS E601, Switzerland). Reference ranges are is $0.34-4.25 \mu \mathrm{IU} / \mathrm{mL}$, for $\mathrm{TSH}$, and 0.61-1.2 ng/dL for fT4.

\section{BIRADS}

MINDRAY D.C-7 real-time US scanner (USA Inc.) with 3.5, 5.0, and 7.5 MHz probes and Doppler facilities were used to assess the intra-abdominal organs, breast, and thyroid. We categorized our patients' breast US reports according to BIRADS ultrasound scores. The radiologist evaluated the lesions according to the lesions' shape, orientation, margin, boundary, echo pattern and posterior acoustic features. As a result of using the fifth edition of the BIRADS assessment categories the lesions were classified as BIRADS 0 (Incomplete-Need Additional Imaging Evaluation), BIRADS 1 (Negative), BIRADS 2 (Benign), BIRADS 3 (Probably benign), BIRADS 4a (low suspicion of malignancy), BIRADS $4 \mathrm{~b}$ (Intermediate suspicion of malignancy), BIRADS 4c (Moderate suspicion of malignancy) and BIRADS 5 (Highly Suggestive of Malignancy), BIRADS 6 (Known Biopsy-Proven Malignancy) (10).

\section{Pelvic Doppler Ultrasonography}

Pelvic Doppler Ultrasonography examinations of the ovaries were performed in all subjects by a radiologist in the study. MINDRAY D.C-7 real-time US scanner (USA Inc.) with 3.5, 5.0, and 7.5 MHz probes and Doppler facilities were used to assess pelvic examination. The US was scheduled in the follicular phase, on the same day that blood samples were obtained, generally. For the patients who were virgin, transabdominal pelvic ultrasound was performed, routinely. The radiologist basely defined myoma uteri according to the location, contour (smooth, lobulated) and echo pattern (anechoic, hyperechoic, complex, hypoechoic, isoechoic). The location and diameter of uterine myoma in this study were not limited, but the number of uterine myomas classified 1 or more than 1 by ultrasonography.

\section{Thyroid ultrasound}

Turkey was a moderately iodine-deficient area before mandatory iodization. Furthermore, in 1999, an obligatory model of iodine prophylaxis was initiated with iodization of household salt. The country is iodine sufficient at the moment (11). Thyroid ultrasound was performed at our clinic by the same radiologist with extensive radiological experience, using a 7.5 MHz linear probe on a MINDRAY DC-7 (USA Inc.) real-time US model with Doppler facilities ultrasound device. The volume of thyroid gland was calculated according to the following formula: lobe volume $(\mathrm{mL})=$ depth $(\mathrm{cm}) \mathrm{x}$ width $(\mathrm{cm}) \times$ length $(\mathrm{cm}) \times 0.52(11,12)$. The thyroid gland was considered to be hypoechoic when its signal was equal or below the echogenicity of the surrounding neck muscle.

\section{Statistical analyses}

SPSS for Windows (ver.11.0, Chicago, IL) was used for statistical analysis. The Shapiro-Wilk and Kolmogorov Smirnov tests were performed to test for normal distribution of variables. In comparison of independent variables that were normally distributed, the student's t-test and analysis of variance were performed, and the variables were expressed as 
mean \pm standard deviation. The independent variables, which were non-normally distributed, were tested by using Mann Whitney $\mathrm{U}$ and Kruskal Wallis tests. $P$ values of 0.05 and lower were accepted as statistically significant.

\section{Results}

We analyzed 251 women, from a total of 8008 patients with benign lesions at least in two different organs including breast, thyroid or uterus at the same time. From 251 patients only 9 patients had benign lesions in all 3 organs, whereas 63 patients had both thyroid nodules and breast lesions and 5 patients had thyroid nodules and uterine myoma, and 7 patients had BIRADS 2,3 lesions and uterine myoma, respectively. The mean age of the patients at the admission to the hospital was $32 \pm 5.7$ years.

From 251 patients, 13 patients had only one uterine myoma and 19 patients had more than one uterine myoma. For breast lesion, patients were divided into two different classes which are cystic and solid benign lesion or BIRADS 1 and BIRADS 2,3 lesions. From 251 patients 45 patients had one cystic breast lesion and 23 patients had one solid lesion, 22 patients had more than one cystic breast lesion and 11 patients had more than one solid lesion, 182 patients had BIRADS 1 lesion, 43 patients had BIRADS 2, 26 patients had BIRADS 3 , respectively. From 251 patients, 13 patients had only one thyroid cystic nodule and 56 patients had a solid nodule, 25 patients had mix semisolid nodule, respectively. 62 patients from 251 women had more than one benign breast lesion.

Comparison of age and hormonal values between the patients with uterine myoma, breast lesion and thyroid nodule and no visible pathology were showed in the table I, II, III, and IV, respectively. We only found significant association between age and existence of uterine myoma and thyroid nodule ( $p=0.008$, for both). Among hormones only TSH was found lower in BIRADS 2,3 lesions than BIRADS $1(p=0.017)$.

Table I: Comparison of age and hormone values between the patients with uterine myoma, breast lesion and no sonographic uterine and breast pathology

\begin{tabular}{lllllll}
\hline & $\begin{array}{l}\text { Uterine Myoma(+) } \\
(\mathrm{n}=19)\end{array}$ & $\begin{array}{l}\text { Uterine Myoma(-) } \\
(\mathrm{n}=231)\end{array}$ & $p$ Value & $\begin{array}{l}\text { BIRADS(1) } \\
(\mathrm{n}=182)\end{array}$ & $\begin{array}{l}\text { BIRADS(2,3) } \\
(\mathrm{n}=69)\end{array}$ & $p$ value \\
\hline Age $(\mathrm{yr})$ & $35 \pm 3.6$ & $31.8 \pm 5.8$ & $\mathbf{0 . 0 0 8}$ & $32.1 \pm 5.5$ & $32.1 \pm 5.8$ & 0.835 \\
FSH $(\mathrm{IU} / \mathrm{L})$ & $8(4.1-14)$ & $5.4(4.3-7.3)$ & 0.704 & $5.4(4.1-7.3)$ & $6.3(4.8-8.3)$ & 0.386 \\
LH $(\mathrm{IU} / \mathrm{L})$ & $5.2(1.9-10.4)$ & $6.4(4.2-10.8)$ & 0.402 & $5.5(5-9.6)$ & $7.6(5.1-16)$ & 0.133 \\
E2 $(\mathrm{pg} / \mathrm{mL})$ & $86(22-109)$ & $47(32-118)$ & 0.428 & $52(31-153)$ & $49(34-76)$ & 0.574 \\
TSH $(\mathrm{IU} / \mathrm{mL})$ & $1.9 \pm 0.8$ & $2.4 \pm 3.4$ & 0.592 & $2.6 \pm 3.7$ & $1.8 \pm 1.5$ & $\mathbf{0 . 0 1 7}$ \\
fT4 $(\mathrm{pmol} / \mathrm{L})$ & $10.1 \pm 6.3$ & $11.9 \pm 9.0$ & 0.491 & $12.4 \pm 6.5$ & $11.6 \pm 9.6$ & 0.536 \\
\hline
\end{tabular}

BIRADS: Breast imaging reporting and data system, FSH: Follicle-stimulating hormone, LH: Luteinizing hormone, E2: Estradiol, TSH: Thyroid stimulating hormone, fT4: free thyroxin 4

Table II: Comparison of age and hormone values between the patients with thyroid nodule and no sonographic thyroid pathology

\begin{tabular}{llll}
\hline & $\begin{array}{l}\text { Thyroid nodule }(+) \\
(\mathrm{n}=6)\end{array}$ & $\begin{array}{l}\text { Thyroid nodule(-) } \\
(\mathrm{n}=245)\end{array}$ & $\begin{array}{l}p \\
\text { value }\end{array}$ \\
\hline Age $(\mathrm{yr})$ & $33.4 \pm 5.4$ & $31.7 \pm 5.6$ & 0.008 \\
FSH $(\mathrm{mlU} / \mathrm{ml})$ & $6.8(4.3-48)$ & $5.3(4.4-7.3)$ & 0.606 \\
LH $(\mathrm{IU} / \mathrm{L})$ & $10.6(4.5-21)$ & $5.8(4-8.4)$ & 0.849 \\
E2 $(\mathrm{pg} / \mathrm{mL})$ & $49.4(31-120)$ & $31.9(21.9-49)$ & 0.564 \\
TSH $(\mathrm{IU} / \mathrm{mL})$ & $2.6 \pm 4.8$ & $2.3 \pm 2.6$ & 0.591 \\
fT4 $(\mathrm{pmol} / \mathrm{L})$ & $10.9 \pm 6.6$ & $12.1 \pm 9.5$ & 0.284 \\
\hline
\end{tabular}

FSH: Follicle-stimulating hormone, LH: Luteinizing hormone, E2: Estradiol, TSH: Thyroid stimulating hormone, fT4: free thyroxin 4.

Table III: Comparison of age and hormone values between the patients with all pathologic images in thyroid, breast and uterus and no sonographic pathology

\begin{tabular}{llll}
\hline & $\begin{array}{l}\text { All organs } \\
(\mathrm{n}=9)\end{array}$ & $\begin{array}{l}\text { No sonographic } \\
\text { pathology }(\mathrm{n}=129)\end{array}$ & $\begin{array}{c}p \\
\text { value }\end{array}$ \\
\hline Age (yr) & $37.2 \pm 3.4$ & $31.2 \pm 5.9$ & 0.003 \\
FSH (mlU/mL (62 patients) & $7.4(5-9)$ & $5.3(4.6-6.9)$ & 0.827 \\
LH (IU/L) (56 patients) & $2.2(2.2-4.8)$ & $3.9(3.1-4.8)$ & 0.429 \\
E2 (pg/mL) (50 patients) & $81(6.6-170)$ & $53(32-138)$ & 0.927 \\
TSH (IU/mL) (229 patients) & $1.5(0.99-3.1)$ & $1.8(0.98-2.9)$ & 0.647 \\
\hline
\end{tabular}

FSH: Follicle-stimulating hormone, LH: Luteinizing hormone, E2: Estradiol, TSH: Thyroid stimulating hormone 
Table IV: Comparison of age and hormonal values between the patients with all pathologic images in only thyroid and breast and no sonographic pathology

\begin{tabular}{llll}
\hline & $\begin{array}{l}\text { Thyroid nodules } \\
\text { and breast lesions } \\
(\mathrm{n}=63)\end{array}$ & $\begin{array}{l}\text { No sonographic } \\
\text { pathology } \\
(\mathrm{n}=129)\end{array}$ & $\begin{array}{c}p \\
\text { value }\end{array}$ \\
\hline Age $(\mathrm{yr})$ & $32 \pm 5.7$ & $31 \pm 5.8$ & 0.412 \\
FSH $(\mathrm{mlU} / \mathrm{mL})$ & $5.8(5-8.3)$ & $6.9(5.3-9.9)$ & 0.521 \\
$\mathrm{LH}(\mathrm{IU} / \mathrm{L})$ & $7.2(4-8.9)$ & $4.8(3.9-8.3)$ & 0.850 \\
E2 $(\mathrm{pg} / \mathrm{mL})$ & $46(31-63)$ & $53(32-138)$ & 0.698 \\
TSH $(\mathrm{IU} / \mathrm{mL})$ & $2.8 \pm 3.1$ & $2.5 \pm 1.99$ & 0.585 \\
fT4 $(\mathrm{pmol} / \mathrm{L})$ & $11.9 \pm 6.6$ & $12.3 \pm 11.4$ & 0.885 \\
\hline
\end{tabular}

FSH: Follicle-stimulating hormone, LH: Luteinizing hormone, E2: Estradiol, TSH: Thyroid stimulating hormone

\section{Discussion}

In this study we only found a relationship between age and existence of myoma uteri and thyroid nodule. ( $p=0.008$, for both). Among hormones, only TSH (Thyroid-stimulating hormone) was found to be lower in BIRADS 2,3 lesions than BIRADS 1 lesions. Until now there is only one study which investigated the frequency of co-occurrence of benign lesions in breast, uterus and thyroid. Although that study (9) demonstrated that women with uterine fibroids have an increased incidence of thyroid nodules and of fibroadenomas of the breast, our study did not show difference between either patient with uterine myoma and benign breast lesion or with thyroid nodule.

Uterine leiomyoma is the most common type of benign neoplasm in the female reproductive system and is the most common indication for hysterectomy in premenopausal women (13). Despite its frequent occurrence, the causes of uterine leiomyoma remain unclear. It is known that the size of uterine leiomyoma is increased by exposure to estrogen derivatives. Similarly, uterine leiomyoma generally occurs in young women. The levels of estrogen receptor in leiomyomas are higher than in normal myometrium, indicating that leiomyoma is more sensitive to stimulation by estrogen (14). In the present clinical study, we aimed to investigate the relationship between estrogen levels and benign lesion in uterus and we showed that there is no relationship between estrogen levels and the existence of myomas in the myometrium, it also revealed that only increasing age impacts the frequency of myomas.

It has been demonstrated that thyroid disorders are more common in women than men (4:1), and obviously estrogens are implicated in this increased incidence. Similarly twentyfive percent of pregnant women have thyroid nodules compared with $9.4 \%$ in those non-pregnant women (15). Thyroid tissues express estrogen receptors (16) and one study showed that a pathogenic role of estrogen in thyroid nodules (7). The study also revealed that estradiol increases proliferation and down-regulates the sodium-iodide symporter gene in FRTL-5 cells, thus promoting the development of iodide-induced thyroid hyperplasia (7). Sodium-iodide symporter is a mechanism for thyroid iodine uptake and thyroid hormone synthesis, which are expressed not only in thyroid tissue but also in different extra-thyroid tissues, including the breast tissue $(17,18)$. Therefore, estrogens may be a common pathophysiological mechanism for the observed increase in both thyroid nodules and breast fibroadenomas in women $(9,17-19)$. However, we did not find any relationship between estrogen levels and the existence of thyroid and benign breast lesions in the present study. Similarly, analyses of our personal data demonstrated that there was no association between anabolic hormones including estrogen and thyroid volume.

Until now there is no study about the relationship between TSH and breast imagination based on BIRADS assessment categories. We found that TSH levels were lower in BIRADS 2,3 lesions than in BIRADS 1 . We think that further investigation should be performed in order to uncover a possible association.

Although the presented retrospective study did not show any relationship between estrogen and myoma uteri, thyroid nodule and breast lesions categorized with BIRADS, further larger prospective studies are needed to investigate the relationship between the same three sample group like our study with taking genetic or environmental factors into account apart from estrogen levels. If these further studies support the results of our study, we can conclude that it is not necessary to scan whether benign lesion exists or not in the other 2 organs concurrently when we observe benign lesion in one organ, on the contrary to the deductions of the previous study (9).

In conclusion, our study did not show an association between estrogen level and the existence of benign lesions in different organs according to radiologic examination in women.

Study limitation: Comparison of age and hormonal values between the patients with existence of both uterine myoma and breast lesions and no sonographic pathology could not be performed by this retrospective study, because of the lack of data and limitation of the design. Similarly, because of the same reason, we could not make a comparison between the existence of both uterine myoma and thyroid nodules and no visible pathology. 
: Acknowledgments: The authors declare no acknowledgements.

Declaration of interest: The authors declare no conflicts of interest.

Funding: None.

Ethical approval: All procedures performed in studies involving human participants were in accordance with the Declaration of Helsinki. The study was approved by the ethics committee.

\section{References}

1. Vilos GA, Allaire C, Laberge PY, Leyland N. The management of uterine leiomyomas. J Obstet Gynaecol Can. 2015; 37(2):157-78.

2. Cramer SF, Patel A. The frequency of uterine leiomyomas. Am J Clin Pathol. 1990;94(4):435-8.

3. Wilkinson S, Forrest AP. Fibro-adenoma of the breast. $\mathrm{Br}$ J Surg. 1985;72(10):838-40.

4. Reinwein D, Benker G, König MP, Pinchera A, Schatz H, Schleusener A. The different types of hyperthyroidism in Europe. Results of a prospective survey of 924 patients. J Endocrinol Invest. 1988;11(3):193-200.

5. Hegedüs L, Bonnema SJ, Bennedbaek FN. Management of simple nodular goiter: current status and future perspectives. Endocr Rev. 2003;24(1):102-32.

6. Krohn K, Führer D, Bayer Y, Eszlinger M, Brauer V, Neumann S, et al. Molecular pathogenesis of euthyroid and toxic multinodular goiter. Endocr Rev. 2005;26(4): 504-24.

7. Manole D, Schildknecht B, Gosnell B, Adams E, Derwahl M. Estrogen promotes growth of human thyroid tumor cells by different molecular mechanisms. J Clin Endocrinol Metab. 2001;86(3):1072-7.

8. Furlanetto TW, Nguyen LQ, Jameson JL. Estradiol increases proliferation and down-regulates the sodium/iodide symporter gene in FRTL-5 cells. Endocrinology 1999;140(12):5705-11.

9. Spinos N, Terzis G, Crysanthopoulou A, Adonakis G, Markou KB, Vervita V, et al. Increased frequency of thyroid nodules and breast fibroadenomas in women with uterine fibroids. Thyroid. 2007;17(12):1257-9. doi: 10.1089/thy.2006.0330

10. Mendelson EB, Böhm-Vélez M, Berg WA, Merritt CRB, Rubin E. ACR BI-RADS ${ }^{\circledR}$ Ultrasound. In: ACR BIRADS $^{\circledR}$ Atlas, Breast Imaging Reporting and Data System. 5th Edition Reston, VA: American College of Radiology; 2013. p.121-31.

11. .Erdoğan MF, Demir O, Emral R, Kamel AN, Erdoğan G. More than a decade of iodine prophylaxis is needed to eradicate goiter among school age children in a moderately iodine-deficient region. Thyroid. 2009;19(3):265-8.

12. Brown MC, Spencer R. Thyroid gland volume estimated by use of ultrasound in addition to scintigraphy. Acta Radiol Oncol Radiat Phys Biol. 1978;17(4):337-41.

13. Wallach EE, Vlahos NF. Uterine myomas: an overview of development, clinical features, and management. Obstet Gynecol. 2004;104(2):393-406.

14. Hunter DS, Hodges LC, Eagon PK, Vonier PM, FuchsYoung R, Bergerson JS, et al. Influence of exogenous estrogen receptor ligands on uterine leiomyoma: evidence from an in vitro/in vivo animal model for uterine fibroids. Environ Health Perspect. 2000;108(5):829-34.

15. Kung AW, Chau MT, Lao TT, Tam SC, Low LC. The effect of pregnancy on thyroid nodule formation. J Clin Endocrinol Metab. 2002;87(3):1010-4.

16. Yane K, Kitahori Y, Konishi N, Okaichi K, Ohnishi T, Miyahara H, et al. Expression of the estrogen receptor in human thyroid neoplasms. Cancer Lett. 1994;84(1):59-66.

17. Spitzweg C, Joba W, Eisenmenger W, Heufelder AE. Analysis of human sodium iodide symporter gene expression in extrathyroidal tissues and cloning of its complementary deoxyribonucleic acids from salivary gland, mammary gland and gastric mucosa. J Clin Endocrinol Metab 1998;83(5):1746-51.

18. Dohán O, De la Vieja A, Paroder V, Riedel C, Artani M, Reed M, et al. The sodium/iodide symporter (NIS): characterization, regulation and medical significance. Endocr Rev. 2003;24(1):48-77.

19. Welcsh PL, Mankoff DA. Taking up iodide in breast tissue. Nature. 2000;406(6797):688-9. 